\title{
A narrative review of lung cancer screening in underserved populations
}

\author{
Omar Toubat ${ }^{1,2}$, Elizabeth A. David ${ }^{2}$ \\ ${ }^{1}$ Keck School of Medicine of USC, University of Southern California, Los Angeles, CA, USA; ${ }^{2}$ Division of Thoracic Surgery, Department of \\ Surgery, Keck School of Medicine of USC, University of Southern California, Los Angeles, CA, USA \\ Contributions: (I) Conception and design: EA David; (II) Administrative support: None; (III) Provision of study materials or patients: None; (IV) \\ Collection and assembly of data: O Toubat; (V) Data analysis and interpretation: Both authors; (VI) Manuscript writing: Both authors; (VII) Final \\ approval of manuscript: Both authors. \\ Correspondence to: Elizabeth A. David, MD, MAS. 1510 San Pablo St., Suite 514, Los Angeles, CA 90033, USA. Email: Elizabeth.David@med.usc.edu.
}

\begin{abstract}
Lung cancer screening with low-dose computed tomography (LDCT) is an effective approach for the early detection of lung cancer and the reduction of lung cancer specific mortality in high risk individuals. Despite recommendations for LDCT screening by the National Comprehensive Cancer Network (NCCN) and the United States Preventive Services Task Force, the utilization of LDCT screening in clinical practice has been low. Moreover, significant disparities in the use of LDCT have been described in underserved populations, including African American or black patients, rural patients with limited access to LDCT screening facilities, and other vulnerable patient groups with known risk factors for developing lung cancer. Several patient, provider, and healthcare systems level approaches have been proposed to mitigate lung cancer screening disparities. Such approaches include raising awareness of LDCT screening benefits and the evidence in support of LDCT screening among healthcare providers, educating patients on LDCT screening and optimizing shared decision-making approaches between patients and providers, and expanding patient access to LDCT screening through free and mobile lung cancer screening programs. As lung cancer screening utilization continues to expand in clinical practice, it will be critical to continue investigating the trends, causes, and outcomes of LDCT screening disparities in underserved populations.
\end{abstract}

Keywords: Lung cancer screening; low-dose computed tomography (LDCT); disparities; underserved

Received: 31 October 2020; Accepted: 26 November 2020; Published online: 22 February 2021.

doi: $10.21037 /$ ccts-20-173

View this article at: http://dx.doi.org/10.21037/ccts-20-173

\section{Introduction}

Lung cancer is the leading cause of cancer related deaths globally (1). In the United States alone, lung cancer accounts for nearly $25 \%$ of all cancer mortality and is estimated to result in 136,000 deaths each year (2). This substantial mortality burden exists, in part, because most lung cancer patients are found to have advanced stage disease at the time of diagnosis (2,3). According to data from the Surveillance, Epidemiology, and End Results (SEER) Program, patients with distant or metastatic disease constitute $57 \%$ of incident lung cancer cases and have an overall survival rate of $6 \%$ at five years (3). The exceedingly high prevalence and mortality associated with advanced stage disease has served as the primary rationale for the development of effective screening approaches in patients at risk of developing lung cancer.

Over the last decade, low-dose computed tomography (LDCT) screening has emerged as an effective modality for the early detection of lung cancers in high-risk patients. In 2011, the National Lung Screening Trial (NLST) showed that the use of LDCT screening was associated with a greater rate of lung cancer detection and a $20 \%$ reduction in lung cancer mortality as compared to surveillance with chest radiography alone (4). These results were recently corroborated by the Dutch-Belgian Lung Cancer Screening (NELSON) Trial, which showed a similar reduction in 
lung cancer mortality in high-risk patients undergoing LDCT screening compared to no screening (5). Following the publication of the NLST trial, both the National Comprehensive Cancer Network (NCCN) (6) and the United States Preventive Services Task Force (USPSTF) (7) developed guidelines recommending lung cancer screening with LDCT. While the guidelines put forth by the NCCN and USPSTF differed slightly in their indications for screening, these recommendations both supported LDCT screening as a validated mechanism to reduce lung cancer specific mortality in select patients.

Despite the clear survival benefit of LDCT screening in appropriate patients, there has been a relatively low adherence to these guidelines in clinical practice (8-10). In addition, several studies have described disparities in the use of LDCT screening in underserved populations, including racial/ethnic minorities $(11,12)$, those living in rural areas with more limited access to care (13), and other vulnerable populations $(14,15)$. Efforts to understand disparities in LDCT screening and their contributing factors have become increasingly relevant, as previous studies have shown that these same underserved populations have a greater incidence of lung cancer and are less likely to receive appropriate treatment (16-19). Therefore, the objective of the present narrative review is to discuss lung cancer screening disparities in underserved populations and to examine methods of improving access to lung cancer screening in these patients. We present the following article in accordance with the Narrative Review reporting checklist (available at https://ccts.amegroups.com/article/ view/10.21037/ccts-20-173/rc).

\section{Methods}

\section{Data source}

The MEDLINE (PubMed) database was queried to identify original research articles describing LDCT screening utilization and outcomes published between January 2013 and October 2020. This search strategy was conducted using the following terms: "disparities" or "inequity" or "underserved populations" or "outcomes" combined with "lung cancer screening" or "lung cancer low dose computed tomography screening" or "lung cancer CT screening". Abstracts were reviewed to identify primary source references that met the objectives of this analysis. Studies were excluded if they were not published in the English language, if the full manuscript text was not available, or if chest radiography served as the primary screening modality.
To provide sufficient background and context for the findings presented in this review, additional searches were performed on referenced literature contained within other narrative reviews published on this topic during the same period.

\section{Rationale and guidelines for lung cancer screening by LDCT}

The primary goal of lung cancer screening efforts has been to improve lung cancer survival through the early detection of malignancy in high-risk patients. This rationale is based on extensive epidemiologic data, which show that patients diagnosed with localized lung cancer have an estimated $54 \%$ five-year survival advantage over those with metastatic disease (3). Given the striking survival discrepancy between early and late stage lung cancer, it was hypothesized that screening based detection with LDCT may shift the burden of newly diagnosed disease into earlier stages and improve survival outcomes.

The NLST provided the first randomized controlled trial evidence in support of this hypothesis. Following the randomization of 53,454 high risk individuals to three rounds of annual LDCT or chest radiography screening, the NLST showed that patients screened with LDCT experienced a higher rate of lung cancer detection and a $20 \%$ relative risk reduction in lung cancer specific mortality (4). Importantly, the greater distribution of stage I lesions identified in the LDCT arm (LDCT $63 \%$ vs. chest radiography $47.6 \%$ ) indicated that the detection and treatment of earlier stage cancers was likely the reason for the survival benefit observed in this trial cohort (4).

Given the results of the NLST, both the NCCN (category I) (6) and USPSTF (grade B) (7) adopted guidelines recommending the use of annual LDCT screening in patients with similar risk profiles to those included in the trial (55-74 years old; $\geq 30$ pack-year smoking history; current or former smoker that has quit within 15 years) (Table 1). In addition to this cohort, the NCCN also extended screening eligibility beyond the NLST criteria to a second group of patients with risk factors such as history of cancer or lung disease, radon or occupational exposure, or family history of lung cancer (6) (Table 1). LDCT screening in this second group was initially given a category $2 \mathrm{~B}$ recommendation by the $\mathrm{NCCN}$, but has since been upgraded to $2 \mathrm{~A}$ (20). Of note, the USPSTF is in the process of revising their guidelines and updated recommendations are forthcoming $(21,22)$.

Despite guideline recommendations and established 
Table 1 Current National Comprehensive Cancer Network and United States Preventive Services Task Force guidelines for LDCT screening

\begin{tabular}{|c|c|}
\hline Organization & LDCT screening criteria \\
\hline \multirow{6}{*}{ NCCN } & - $\quad$ Age: $55-77$ years \\
\hline & - $\quad$ Smoking history: $\geq 30$ pack-years \\
\hline & - $\quad$ Smoking status: current smokers or former smokers who have quit within 15 years \\
\hline & - $\quad$ Age: $\geq 50$ years \\
\hline & - $\quad$ Smoking history: $\geq 20$ pack-years \\
\hline & $\begin{array}{l}\text { At least one additional risk factor: contact with radon, asbestos, or other cancer causing agents (not including } \\
\text { second-hand smoke); personal history of cancer or lung disease; family history of lung cancer }\end{array}$ \\
\hline USPSTF & - $\quad$ Smoking status: current smokers or former smokers who have quit within 15 years \\
\hline
\end{tabular}

*, USPSTF guidelines for LDCT screening are currently in the process of being revised. LDCT, low-dose computed tomography; NCCN, National Comprehensive Cancer Network; USPSTF, United States Preventive Services Task Force.

evidence in support of LDCT screening, there has been a relatively low uptake in clinical practice. In two separate analyses using data from the National Health Interview Survey (NHIS), Jemal et al. (9) and Richards et al. (10) independently estimated that only $4 \%$ of eligible individuals received LDCT screening in accordance with USPSTF guidelines in 2015. For comparison, that same year it was estimated that $8.5 \%$ of patients received lung cancer screening by chest radiography, despite no data supporting its efficacy (10). More recently, a Centers for Disease Control and Prevention (CDC) analysis using survey data collected from ten states in 2017 estimated that $12.7 \%$ of USPSTF eligible individuals received LDCT screening (23). While this positive trend is encouraging, these data underscore the significant and continued underutilization of LDCT screening in eligible patients in real world practice. Studies have indicated that racial/ethnic minorities and those with limited access to care are among those most affected by poor screening uptake. Below, we summarize results from pertinent studies that describe these disparities.

\section{Disparities and outcomes of lung cancer screening in underserved populations}

\section{Race/ethnicity}

Racial and ethnic disparities are well described in the thoracic oncology literature. In particular, several previous studies have shown that underrepresented minority populations experience a higher incidence of lung cancer and are less likely to receive guideline concordant treatment at various stages of disease $(16,18,19,24-26)$. Recently, there has been accumulating evidence to suggest that this pattern of racial disparities may extend into the receipt of LDCT screening (Table 2).

In a retrospective analysis of 262 individuals undergoing LDCT screening at a community center, Richmond et al. showed that a significantly lower proportion of black patients were screened as compared to their white counterparts (27). Similar trends have also been described among patients at academic facilities. In 2018, Japuntich et al. conducted a cross-sectional survey of 200 current or former smokers at their institution to compare screening eligibility and utilization between black and non-black individuals (28). Their work showed that among those eligible for screening, non-black patients were 2.8-times more likely to be screened than black patients (28). Similar disparities were described in a recently published analysis of patients at an academic safety net hospital by Steiling et al. (12). Although these authors reported a relatively high overall screening rate in their eligible patient cohort (16.1\%), they found that black patients were significantly 
Table 2 Studies describing racial disparities in LDCT screening

\begin{tabular}{|c|c|c|c|c|c|c|}
\hline Author & Study type & $\begin{array}{l}\text { Data } \\
\text { source }\end{array}$ & $\begin{array}{l}\text { No. } \\
\text { patients }\end{array}$ & $\begin{array}{l}\text { Years } \\
\text { studied }\end{array}$ & $\begin{array}{l}\text { Research } \\
\text { question/objective }\end{array}$ & Main finding(s) \\
\hline $\begin{array}{l}\text { Lake } \\
\text { et al. (11) }\end{array}$ & $\begin{array}{l}\text { Retrospective, } \\
\text { observational }\end{array}$ & Institutional & 675 & 2015-2017 & $\begin{array}{l}\text { To explore racial differences } \\
\text { in lung cancer screening } \\
\text { outcomes, including differences } \\
\text { in LDCT rates, follow-up, and } \\
\text { cancer diagnoses in patients } \\
\text { with positive baseline scans. }\end{array}$ & $\begin{array}{l}\text { Black individuals had significantly lower } \\
\text { odds of receiving LDCT after controlling } \\
\text { for individual lung cancer risk factors and } \\
\text { neighborhood-level factors. } \\
\text { - Black individuals also demonstrated a } \\
\text { trend toward delayed follow-up, decreased } \\
\text { adherence, and loss to follow-up. }\end{array}$ \\
\hline $\begin{array}{l}\text { Steiling } \\
\text { et al. (12) }\end{array}$ & $\begin{array}{l}\text { Retrospective, } \\
\text { observational }\end{array}$ & Institutional & 2,978 & 2015-2017 & $\begin{array}{l}\text { To determine institutional } \\
\text { screening rate and to identify } \\
\text { socioeconomic } \\
\text { barriers to lung cancer } \\
\text { screening }\end{array}$ & $\begin{array}{l}\text { - Lung cancer screening rate was found to } \\
\text { be } 16.1 \% \text {. Patient factors including older } \\
\text { age, African American race, and lower } \\
\text { median income were associated with not } \\
\text { being screening. }\end{array}$ \\
\hline $\begin{array}{l}\text { Japuntich } \\
\text { et al. (28) }\end{array}$ & $\begin{array}{l}\text { Cross-sectional } \\
\text { (survey) }\end{array}$ & Institutional & 200 & 2016 & $\begin{array}{l}\text { What is the USPSTF eligibility } \\
\text { and LDCT screening rate } \\
\text { among Black and non-Black } \\
\text { patients? }\end{array}$ & $\begin{array}{l}\text { - Black patients were less likely to qualify for } \\
\text { screening and disproportionately less likely } \\
\text { to be screened for lung cancer compared } \\
\text { with non-Black patients. }\end{array}$ \\
\hline $\begin{array}{l}\text { Sesti } \\
\text { et al. (29) }\end{array}$ & $\begin{array}{l}\text { Retrospective, } \\
\text { observational } \\
\text { analysis of a } \\
\text { randomized } \\
\text { controlled trial }\end{array}$ & NLST & 14,000 & 2002-2004 & $\begin{array}{l}\text { To determine predictors of } \\
\text { follow-up after a } \\
\text { positive lung cancer } \\
\text { screening test }\end{array}$ & $\begin{array}{l}\text { Black race and current smoking status } \\
\text { were associated with lower rates of follow } \\
\text { up after positive LDCT test among NLST } \\
\text { participants. }\end{array}$ \\
\hline
\end{tabular}

LDCT, low-dose computed tomography; USPSTF, U.S. Preventive Services Task Force; NLST, National Lung Screening Trial; NSCLC, Non-small cell lung cancer.

less likely than white patients to receive LDCT screening by bivariate analysis (12). In another study, Lake et al. showed that the disproportionate screening rates among black individuals referred to their center persisted even after controlling for other patient characteristics, such as age, sex, BMI, smoking status, family history of lung cancer, and chronic obstructive pulmonary disease (COPD) (11). While the exact reasons for the institution-level racial disparities are unclear, these findings indicate that additional factors other than patient clinical characteristics may contribute to the lower LDCT screening rates among black patients.

In addition to rates of screening, recent studies have also described racial differences in the patterns of clinical follow up and treatment after positive tests. Rather surprisingly, such studies have largely been conducted using data from the NLST database. Sesti et al. performed a multivariate analysis of factors predictive of follow up after a positive LDCT test in the NLST (29). Their work demonstrated that black race was associated with a significantly lower likelihood of follow up compared to white race independent of sex, marital status, and smoking status (29). Balekian et al. evaluated disparities in the receipt of surgery for NLST participants diagnosed with early stage lung cancer during the trial period (30). Their analysis demonstrated 
that black male participants with identified clinical stage I tumors were $28 \%$ less likely than white male participants to undergo curative intent resection (30). In addition, Balekian et al. observed that even among NLST participants receiving surgery for clinical stage I lesions, black men were more likely to undergo limited resection (defined as wedge resection or segmentectomy) compared to white men who were more likely to undergo full resection (defined as lobectomy, bilobectomy, or pneumonectomy) (30). Of note, analysis of surgical interventions between black and white women NLST participants did not yield similar trends.

\section{Patients living in rural areas}

In addition to racial/ethnic disparities, differences in LDCT screening availability and access to LDCT screening centers have been described for patients living in rural areas (31) (Table 3). Shortly after the USPSTF's endorsement of LDCT screening, Eberth et al. evaluated the geographic distribution of LDCT screening centers in the United States and correlated their locations with population estimates of lung cancer incidence, mortality, and smoking prevalence (32). Their analysis showed that most active LDCT screening centers in 2014 were predominately located within urban counties in Northeastern states (32). Conversely, rural counties with high lung cancer burdens in states such as Mississippi, Missouri, Oklahoma, and West Virginia were found to have low screening center availability (32). Rather surprisingly, there were 11 states that did not have any active screening centers at that time (32).

The same group conducted a follow-up analysis using data from 2017 (13). This study showed that despite an 8.6-fold increase in the total number of active LDCT screening centers in the United States, pronounced disparities continued to exist in the distribution of these centers between rural and urban areas (13). Kale et al. performed the most recent analysis on this topic. Their work demonstrated that Southeastern states continue to have a fewer active LDCT screening centers and higher lung cancer and smoking burdens compared to states in the Northeast and Southwest (33). Importantly, they also show a slower rate of increase of new screening facilities in Southeastern states, suggesting that disparities will continue to persist unless concerted efforts are made to improve LDCT facility development in these regions.

To understand the impact of screening center geographic variability on patient access, Tailor et al. evaluated the distribution of United States smokers by census tract and their driving distance to American College of Radiology accredited LDCT screening facilities (34). Their work estimated that $82 \%$ of cigarette smokers reside within 15 -miles of an accredited screening facility (34). While this suggests that travel distance alone may not serve as a significant barrier to LDCT screening access for the majority of smokers, the significant inter- and intra-state geographic variation does indicate that certain populations may be relatively disadvantaged (34). It is also important to note that transportation methods, costs, and other patient-level factors influencing travel capacity were not included in their analysis.

Building from their previous work, Tailor et al. conducted an analysis of factors associated with geospatial access to LDCT screening facilities (35). Using multivariable regression modeling, they examined census tract population characteristics predictive of travel distance to nearest screening centers (35). Although their model identified multiple demographic and socioeconomic status characteristics associated with greater traveling distances to screening centers (e.g., older age, uninsured/Medicaid, and lower formal education level), population density was found to be the greatest determinant of facility access (35). The work by Tailor et al. not only underscores the importance of sociodemographic and geographic factors in determining access to screening facilities, but also suggests that these factors may have downstream effects on screening utilization rates.

\section{Other vulnerable patient populations}

While much of the lung cancer screening literature has focused on racial/ethnic and geographic inequities, there is an emerging interest in studying screening outcomes in other vulnerable patient groups, including the uninsured/Medicaid insured and sexual minorities (Table 4). The concern for LDCT screening disparities in these groups largely stems from previous studies demonstrating a disproportionately high prevalence of tobacco smoking and poor screening uptake for other cancer types in these cohorts (39-44).

Zahnd et al. analyzed demographic and clinical factors associated with lung cancer screening uptake using the 2017 CDC Behavioral Risk Factor Surveillance System data (36). Evaluating survey responses from 4,374 individuals across 10 states, they showed that annual LDCT screening utilization was significantly lower among uninsured individuals than those with any form of insurance $(4.0 \%$ vs. $15.2 \%$, $\mathrm{P}<0.001)(36)$. Variables associated with increased screening rates in their analysis included asthma and COPD (36). Zgodic et al. validated these findings in a follow up analysis 
Table 3 Studies describing rural/geographic disparities in LDCT screening

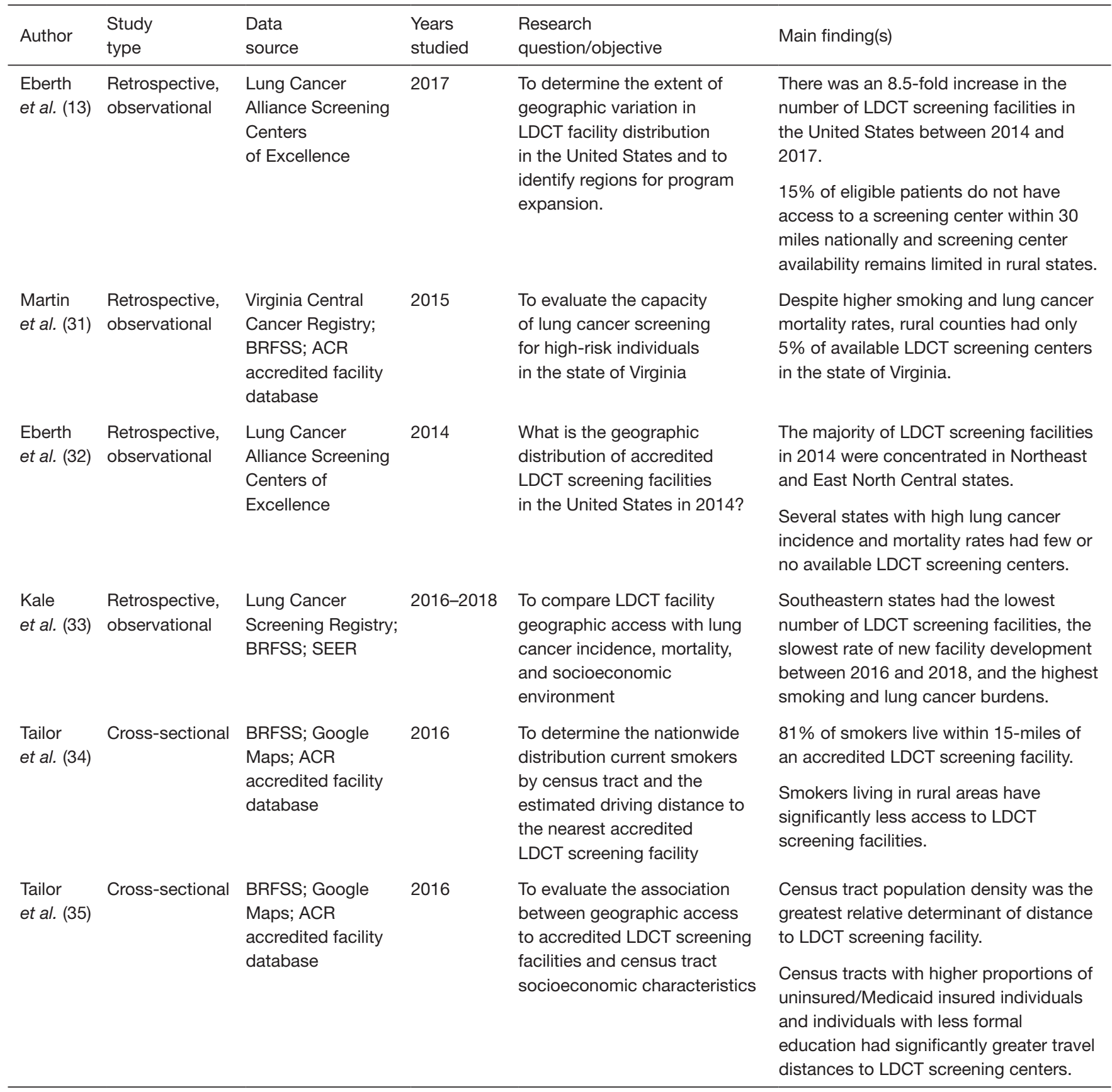

LDCT, low-dose computed tomography; BRFSS, Behavioral Risk Factor Surveillance System Survey; SEER, Surveillance, Epidemiology, and End Results; ACR, American College of Radiology.

showing that uninsured status remained significantly predictive of lower odds of receiving lung cancer screening after controlling for sex, age, race/ethnicity, marital status, history of cancer or chronic respiratory disease by multivariable regression [odds ratio (OR) 0.28, $95 \%$ CI,
$0.12-0.65)(37)$.

Matthews et al. estimated the prevalence of cigarette smoking and LDCT screening eligibility among sexual minorities using survey data from the 2012-2013 National Epidemiologic Survey on Alcohol and Related Conditions 
Table 4 Studies describing LDCT screening disparities in other vulnerable populations, including the uninsured and sexual minorities

\begin{tabular}{|c|c|c|c|c|c|c|}
\hline Author & Study type & $\begin{array}{l}\text { Data } \\
\text { source }\end{array}$ & $\begin{array}{l}\text { No. } \\
\text { patients }\end{array}$ & $\begin{array}{l}\text { Years } \\
\text { studied }\end{array}$ & $\begin{array}{l}\text { Research } \\
\text { question/objective }\end{array}$ & $\begin{array}{l}\text { Main } \\
\text { finding(s) }\end{array}$ \\
\hline $\begin{array}{l}\text { Matthews } \\
\text { et al. (15) }\end{array}$ & $\begin{array}{l}\text { Retrospective, } \\
\text { observational }\end{array}$ & NESARC-III & 9,635 & 2012-2013 & $\begin{array}{l}\text { To compare cigarette } \\
\text { smoking prevalence and } \\
\text { LDCT screening eligibility } \\
\text { between U.S. adults of } \\
\text { different sexual orientations }\end{array}$ & $\begin{array}{l}\text { Sexual minorities had higher rates of } \\
\text { smoking and LDCT eligibility, with the } \\
\text { greatest rates observed among bisexual } \\
\text { women and men. }\end{array}$ \\
\hline $\begin{array}{l}\text { Zgodic } \\
\text { et al. (37) }\end{array}$ & Cross-sectional & BRFSS & 4,373 & 2017 & $\begin{array}{l}\text { To determine demographic, } \\
\text { financial, and health care } \\
\text { factors associated with } \\
\text { LDCT screening uptake in a } \\
\text { population based survey }\end{array}$ & $\begin{array}{l}\text { - LDCT screening rates were significantly } \\
\text { higher among those who were younger, } \\
\text { insured, had chronic respiratory conditions, } \\
\text { were single/separated/windowed, or who } \\
\text { had previous cancer diagnoses. }\end{array}$ \\
\hline $\begin{array}{l}\text { Veliz } \\
\text { et al. (38) }\end{array}$ & $\begin{array}{l}\text { Retrospective, } \\
\text { observational }\end{array}$ & BRFSS & 20,685 & 2017 & $\begin{array}{l}\text { To evaluate the association } \\
\text { between sexual orientation } \\
\text { and the eligibility for and } \\
\text { receipt of LDCT lung cancer } \\
\text { screening }\end{array}$ & $\begin{array}{l}\text { Rates of LDCT eligibility are twice as high } \\
\text { for sexual minorities than heterosexuals. } \\
\text { There were no statistically significant } \\
\text { differences in the rates of LDCT screening } \\
\text { by sexual orientation group. }\end{array}$ \\
\hline
\end{tabular}

LDCT, low-dose computed tomography; BRFSS, Behavioral Risk Factor Surveillance System Survey; NESARC-III, National Epidemiologic Survey on Alcohol and Related Conditions.

(NESARC-III) (15). Overall, 11.2\% of respondents in their sample were found to meet eligibility criteria for LDCT screening. When examining screening eligibility by sexual orientation, they found that bisexual women (26.9\%) and bisexual men $(24.5 \%)$ had the highest rates of screening eligibility (15). After adjusting for potential confounding variables including race, education level, personal income, employment status, relationship status, health insurance status, geographic location, and metropolitan area, only bisexual women were found to have a significantly higher proportion of screening eligibility (15). Using the same NESARC-III dataset, Veliz et al. also evaluated the association between sexual orientation and indication for LDCT screening (38). After validating the relationship between sexual minority status and screening eligibility, they went on to show no statistically significant differences in the relative rates of LDCT screening by sexual orientation (38). This suggests that although a greater proportion of sexual minorities meet indications for LDCT screening based on current screening guidelines, they are not being screened at a higher rate than heterosexual individuals in clinical practice. Ultimately, given the early data gathered from these studies, continued investigation into rates of
LDCT screening in sexual minorities and other vulnerable populations at high-risk of developing lung cancer is warranted.

\section{Methods to improve lung cancer screening in underserved populations}

In addition to the study of LDCT screening disparities, several reports have sought to evaluate methods of improving rates of screening in clinical practice. These approaches include patient-, provider-, and system-level interventions intended to increase awareness of LDCT screening efficacy and/or lower barriers to accessing this technology (Figure 1).

\section{Improving awareness of LDCT screening among bealthcare providers}

One of the most critical factors limiting the utilization of LDCT screening is the lack of familiarity with the guidelines among members of the medical community. Importantly, previous studies have demonstrated that physicians who are aware of the guidelines are more likely to initiate discussions of lung cancer screening with their 


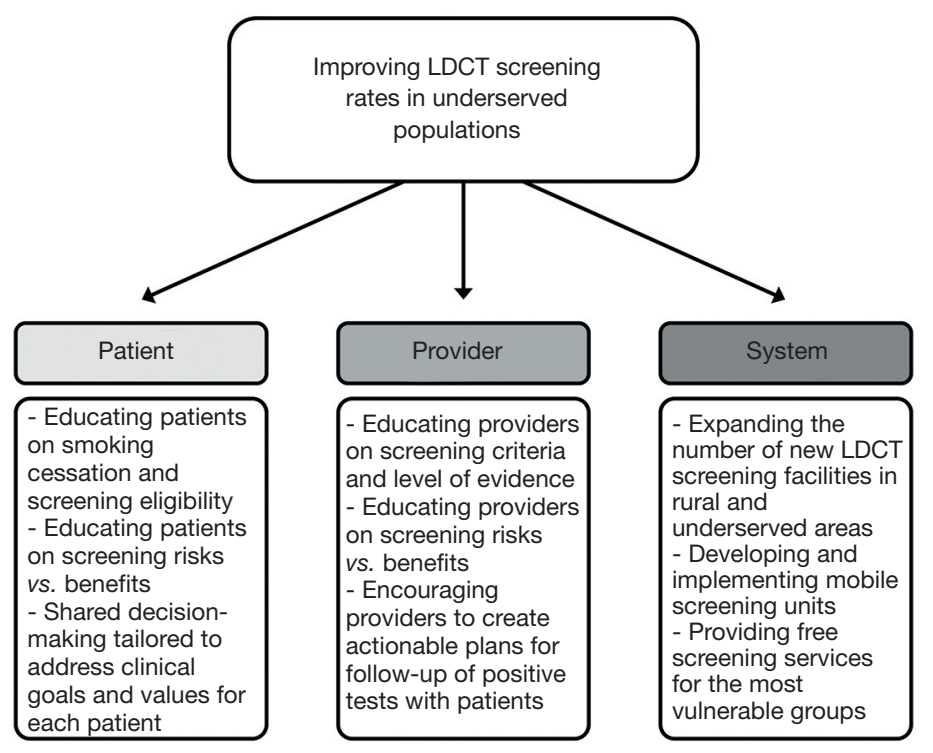

Figure 1 Flow chart outlining patient, provider, and system-level approaches to improve LDCT screening rates in underserved populations. LDCT, low-dose computed tomography.

patients (45) and order LDCT screening tests $(45,46)$. However, since the USPSTF's endorsement of LDCT screening, multiple institutional reports have shown that primary care physicians in underserved areas have a relatively limited understanding of the guidelines and their supporting evidence (47-52). While the exact reasons for this uncertainty are not well known, discordance between NCCN and USPSTF indications for screening, lack of familiarity of the survival benefit associated with LDCT screening, and concerns regarding false positive rates and excess harms to the patient may all play a role $(49-51,53)$. Efforts to familiarize healthcare providers with these topics through the distribution of educational materials and group based learning methods have been shown to be feasible at individual centers (54). To date, data demonstrating the effectiveness of these interventions on the national level are currently lacking.

\section{Patient engagement and shared decision-making}

An additional approach to improving screening rates has been to directly familiarize patients with LDCT screening. Consistent with the data on the lack of provider knowledge of screening guidelines, previous surveys conducted at single institutions (55-57) and in nationally representative samples have demonstrated that most high risk patients are not aware of the purpose of LDCT screening $(58,59)$. In addition, some studies have indicated that current smokers are less informed of LDCT screening than former smokers $(58,59)$. This suggests that existing opportunities for physicians to counsel patients on smoking cessation can also be used to discuss LDCT screening.

Beginning in 2015, shared decision-making has been required by the Centers for Medicare and Medicaid Services (CMS) for LDCT screening reimbursement (60). Since this time, multiple studies have tested the efficacy of shared decision-making processes in the education of patients regarding LDCT. Some reports have demonstrated that shared decision-making approaches with the use of decision aids to supplement standard information materials improves patient knowledge and perceived benefits of screening $(55,56,61,62)$. However, despite improvements in patient knowledge regarding LDCT screening, some studies have shown that shared decision-making alone does not appear sufficient to uniformly improve rates of LDCT screening completion (62-65). These studies indicate that the most effective shared decision-making approaches should not only discuss screening eligibility and the risks/benefits of screening, but should also actively assess the patient's willingness and ability to undergo screening and subsequent treatment should cancer be detected (66). Finally, some studies have suggested that the formal requirement of 
shared decision-making may also serve as a barrier to lung cancer screening in certain patients. In a national survey of 293 primary care physicians, Eberth et al. found that most providers identified competing health priorities of the patient and lack of time as significant barriers to engaging in shared decision-making (67). As a result, despite over $75 \%$ of physician respondents agreeing with the benefits of LDCT screening for high-risk individuals, only $5 \%$ reported using the CMS billing code for shared decisionmaking reimbursement (67). Other studies have also highlighted time constraints and perceived challenges with patient comprehension of screening as critical barriers in the effective shared decision-making process $(68,69)$.

\section{Improving access to LDCT screening in underserved populations}

We previously highlighted the geographic and transportation challenges disproportionately experienced by underserved patients seeking to access LDCT screening facilities. Consistent with these disparities, surveys of underserved patients and their providers have consistently identified perceived financial costs as a potentially prohibitive factor against willingness to undergo LDCT screening $(57,70,71)$. Adding validity to these concerns, Febbo et al. recently estimated that the average out-ofpocket costs associated with LDCT screening at accredited imaging centers is \$583 (range, \$49-2,409) (72).

To combat this financial burden, some groups have trialed free screening services for at-risk patients. McKee et al. described their experience with the first major free screening service beginning shortly after the NCCN adopted screening guidelines in 2012 (73). In 10 months, their group successfully screened a total of 500 patients, yielding a positivity rate similar to that of the NLST (73). Their work has served as proof of concept for subsequent efforts. More recently, a second analysis by Simmerman et al. validated the previous success described by McKee et al. (74). They screened 264 individuals in their program and had a $2.2 \%$ lung cancer detection rate $(v s .1 .1 \%$ in NLST), of which $63 \%$ were stage I tumors (vs. $63 \%$ in NLST) (74). Concerns regarding the profitability of free screening programs have also recently been addressed. After 2.5 years of an institutional free screening program guided by the NCCN screening inclusion criteria, Chung et al. conducted a profitability analysis and found a $\$ 212$ gross margin per encounter (75). The authors found that this revenue was primarily driven by downstream surgical interventions, as $74 \%$ of their screening cohort had operable lesions (75). While this analysis underscores the importance of close patient follow-up to achieve optimal financial and clinical benefits from free screening, the generalizability of the profit analysis performed by Chung et al. may be limited by the high rate of follow-up in their sample $59 \%$ of LDCT screens associated with downstream referrals, follow-ups, or interventions) (75).

In addition to free screening programs, some studies have proposed using mobile screening units to improve patient access to LDCT. Raghavan et al. published preliminary data describing the use of a mobile LDCT unit as a means of screening 550 uninsured/Medicaid insured patients (76). Of the $12(2.2 \%)$ individuals with identifiable lung cancer, 6 $(50 \%)$ were found to have surgically amenable disease and were able to successfully undergo resection with curative intent (76). A second pilot analysis by Headrick et al. showed similar success screening 548 high risk individuals with a mobile LDCT unit (77). Despite only having a positivity rate of $1 \%$, because $80 \%$ of positive cases were early stage tumors managed by surgery or stereotactic body radiation therapy, Headrick et al.'s mobile program maintained the ability to generate a revenue (77). In addition to patients with identified lung cancer, 51 individuals were found to have significant pulmonary findings (Lung-RADS 3 or 4) by LDCT screening (77). Of these, $67 \%$ followed up for further testing as advised (77). Collectively, these studies demonstrate that with appropriate patient follow-up, free or mobile LDCT screening programs can potentially serve as clinically effective and commercially viable options to improve lung cancer screening availability for underserved patients.

\section{Conclusions}

LDCT screening is an effective approach for the early detection of lung cancer and the reduction of lung cancer specific mortality in high risk individuals. However, the utilization of LDCT screening in clinical practice has been slow, with current estimates suggesting that $\sim 12 \%$ of eligible individuals in the United States receive appropriate screening. Significant disparities in the use of LDCT have been described among black patients, rural patients, and other underserved populations. There have been several proposed efforts to mitigate these disparities, including raising awareness of LDCT screening benefits among healthcare providers, improving shared decision-making approaches between patients and providers, and expanding patient access to free and mobile screening programs. As the 
indications for and utilization of LDCT screening evolve, continued investigations into the causes and outcomes of LDCT disparities are warranted.

\section{Acknowledgments}

Funding: This research did not receive any specific grant from funding agencies in the public, commercial, or notfor-profit sectors. O.T. is supported in part by NIH award F30HL154324 outside of the submitted work.

\section{Footnote}

Provenance and Peer Review: This article was commissioned by the Guest Editor (Sandra Starnes) for the series "Lung Cancer Screening" published in Current Challenges in Thoracic Surgery. The article has undergone peer review.

Reporting Checklist: The authors have completed the Narrative Review reporting checklist. Available at https:// ccts.amegroups.com/article/view/10.21037/ccts-20-173/rc

Conflicts of Interest: Both authors have completed the ICMJE uniform disclosure form (available at https://ccts. amegroups.com/article/view/10.21037/ccts-20-173/coif). The series "Lung Cancer Screening" was commissioned by the editorial office without any funding or sponsorship. The authors have no other conflicts of interest to declare.

Ethical Statement: The authors are accountable for all aspects of the work in ensuring that questions related to the accuracy or integrity of any part of the work are appropriately investigated and resolved.

Open Access Statement: This is an Open Access article distributed in accordance with the Creative Commons Attribution-NonCommercial-NoDerivs 4.0 International License (CC BY-NC-ND 4.0), which permits the noncommercial replication and distribution of the article with the strict proviso that no changes or edits are made and the original work is properly cited (including links to both the formal publication through the relevant DOI and the license). See: https://creativecommons.org/licenses/by-nc-nd/4.0/.

\section{References}

1. Bray F, Ferlay J, Soerjomataram I, et al. Global cancer statistics 2018: GLOBOCAN estimates of incidence and mortality worldwide for 36 cancers in 185 countries. CA Cancer J Clin 2018;68:394-424.

2. Siegel RL, Miller KD, Jemal A. Cancer statistics, 2020. CA Cancer J Clin 2020;70:7-30.

3. National Cancer Institute. Surveillance, Epidemiology, and End Results Program: Cancer Statistics. Cancer Stat Facts. Accessed October 10, 2020. Available online: https://seer. cancer.gov/statfacts/html/lungb.html

4. Aberle DR, Adams AM, Berg CD, et al. Reduced LungCancer Mortality with Low-Dose Computed Tomographic Screening. N Engl J Med 2011;365:395-409.

5. de koning HJ, Van Der Aalst CM, De Jong PA, et al. Reduced lung-cancer mortality with volume CT screening in a randomized trial. N Engl J Med 2020;382:503-13.

6. Wood DE, Eapen GA, Ettinger DS, et al. Lung cancer screening: Clinical practice guidelines in oncology. J Natl Compr Cancer Netw 2012;10:240-65.

7. Moyer VA; U.S. Preventive Services Task Force. Screening for Lung Cancer: U.S. Preventive Services Task Force Recommendation Statement. Ann Intern Med 2014;160:330-8.

8. Hoffman RM, Atallah RP, Struble RD, et al. Lung Cancer Screening with Low-Dose CT: a Meta-Analysis. J Gen Intern Med 2020;35:3015-25.

9. Jemal A, Fedewa SA. Lung cancer screening with lowdose computed tomography in the United States - 2010 to 2015. JAMA Oncol 2017;3:1278-81.

10. Richards TB, Doria-Rose VP, Soman A, et al. Lung Cancer Screening Inconsistent With U.S. Preventive Services Task Force Recommendations. Am J Prev Med 2019;56:66-73.

11. Lake M, Shusted CS, Juon HS, et al. Black patients referred to a lung cancer screening program experience lower rates of screening and longer time to follow-up. BMC Cancer 2020;20:561.

12. Steiling K, Loui T, Asokan S, et al. Age, Race, and Income Are Associated With Lower Screening Rates at a Safety Net Hospital. Ann Thorac Surg 2020;109:1544-50.

13. Eberth JM, Bozorgi P, Lebrón LM, et al. Geographic availability of low-dose computed tomography for lung cancer screening in the United States, 2017. Prev Chronic Dis 2018;15:E119.

14. Flores EJ, Park ER, Irwin KE. Improving Lung Cancer Screening Access for Individuals With Serious Mental Illness. J Am Coll Radiol 2019;16:596-600.

15. Matthews AK, McCabe SE, Lee JGL, et al. Differences in smoking prevalence and eligibility for low-dose computed tomography (LDCT) lung cancer screening among older 
U.S. adults: role of sexual orientation. Cancer Causes Control 2018;29:769-74.

16. Bach PB, Cramer LD, Warren JL, et al. Racial differences in the treatment of early-stage lung cancer. N Engl J Med. 1999;341:1198-205.

17. Atkins GT, Kim T, Munson J. Residence in rural areas of the United States and lung cancer mortality: Disease incidence, treatment disparities, and stage-specific survival. Ann Am Thorac Soc 2017;14:403-11.

18. Ebner PJ, Ding L, Kim AW, et al. The Effect of Socioeconomic Status on Treatment and Mortality in Non-Small Cell Lung Cancer Patients. Ann Thorac Surg 2020;109:225-32.

19. Toubat O, Atay SM, Kim AW, et al. Disparities in Guideline-Concordant Treatment for Pathologic N1 Non-Small Cell Lung Cancer. Ann Thorac Surg 2020;109:1512-20.

20. Wood DE, Kazerooni EA, Baum SL, et al. Lung cancer screening, version 3.2018. J Natl Compr Canc Netw 2018;16:412-41.

21. U.S. Preventive Services Task Force. Lung Cancer: Screening. Published 2013. Accessed October 10, 2020. Available online: https://www. uspreventiveservicestaskforce.org/uspstf/recommendation/ lung-cancer-screening

22. United States Preventive Services Task Force. Lung Cancer: Screening 2020. Accessed October 17, 2020. Available online: https://www. uspreventiveservicestaskforce.org/uspstf/draft-updatesummary/lung-cancer-screening-2020

23. Richards TB, Soman A, Thomas CC, et al. Screening for Lung Cancer - 10 States, 2017. MMWR Morb Mortal Wkly Rep 2020;69:201-6.

24. Soneji S, Tanner NT, Silvestri GA, et al. Racial and Ethnic Disparities in Early-Stage Lung Cancer Survival. Chest 2017;152:587-97.

25. Wisnivesky JP, McGinn T, Henschke C, et al. Ethnic disparities in the treatment of stage I non-small cell lung cancer. Am J Respir Crit Care Med 2005;171:1158-63.

26. Earle CC, Neumann PJ, Gelber RD, et al. Impact of referral patterns on the use of chemotherapy for lung cancer. J Clin Oncol 2002;20:1786-92.

27. Richmond J, Mbah OM, Dard SZ, et al. Evaluating Potential Racial Inequities in Low-dose Computed Tomography Screening for Lung Cancer. J Natl Med Assoc 2020;112:209-14.

28. Japuntich SJ, Krieger NH, Salvas AL, et al. Racial Disparities in Lung Cancer Screening: An Exploratory
Investigation. J Natl Med Assoc 2018;110:424-7.

29. Sesti J, Sikora TJ, Turner DS, et al. Disparities in FollowUp After Low-Dose Lung Cancer Screening. Semin Thorac Cardiovasc Surg 2020;32:1058-63.

30. Balekian AA, Wisnivesky JP, Gould MK. Surgical Disparities Among Patients With Stage I Lung Cancer in the National Lung Screening Trial. Chest 2019;155:44-52.

31. Martin AN, Hassinger TE, Kozower BD, et al. Disparities in Lung Cancer Screening Availability: Lessons From Southwest Virginia. Ann Thorac Surg 2019;108:412-6.

32. Eberth JM, Qiu R, Adams SA, et al. Lung cancer screening using low-dose CT: The current national landscape. Lung Cancer 2014;85:379-84.

33. Kale MS, Wisnivesky J, Taioli E, et al. The Landscape of US Lung Cancer Screening Services. Chest 2019;155:900-7.

34. Tailor TD, Choudhury KR, Tong BC, et al. Geographic Access to CT for Lung Cancer Screening: A Census TractLevel Analysis of Cigarette Smoking in the United States and Driving Distance to a CT Facility. J Am Coll Radiol 2019;16:15-23.

35. Tailor TD, Tong BC, Gao J, et al. A Geospatial Analysis of Factors Affecting Access to CT Facilities: Implications for Lung Cancer Screening. J Am Coll Radiol 2019;16:1663-8.

36. Zahnd WE, Eberth JM. Lung Cancer Screening Utilization: A Behavioral Risk Factor Surveillance System Analysis. Am J Prev Med 2019;57:250-5.

37. Zgodic A, Zahnd WE, Miller DP, et al. Predictors of Lung Cancer Screening Utilization in a Population-Based Survey. J Am Coll Radiol 2020;17:1591-601.

38. Veliz P, Matthews AK, Arslanian-Engoren C, et al. LDCT lung cancer screening eligibility and use of CT scans for lung cancer among sexual minorities. Cancer Epidemiol 2019;60:51-4.

39. Williams LB, McCall A, Looney SW, et al. Demographic, psychosocial, and behavioral associations with cancer screening among a homeless population. Public Health Nurs 2018;35:281-90.

40. Zhu SH, Anderson CM, Wong S, et al. The Growing Proportion of Smokers in Medicaid and Implications for Public Policy. Am J Prev Med 2018;55:S130-7.

41. Irwin KE, Henderson DC, Knight HP, et al. Cancer care for individuals with schizophrenia. Cancer 2014;120:323-34.

42. Aggarwal A, Pandurangi A, Smith W. Disparities in breast and cervical cancer screening in women with mental illness: A systematic literature review. Am J Prev Med 2013;44:392-8. 
43. Kalkhoran S, Thorndike AN, Rigotti NA, et al. Cigarette Smoking and Quitting-Related Factors Among US Adult Health Center Patients with Serious Mental Illness. J Gen Intern Med 2019;34:986-91.

44. Johnson SE, Holder-Hayes E, Tessman GK, et al. Tobacco Product Use among Sexual Minority Adults: Findings from the 2012-2013 National Adult Tobacco Survey. Am J Prev Med 2016;50:e91-100.

45. Raz DJ, Wu GX, Consunji M, et al. The Effect of Primary Care Physician Knowledge of Lung Cancer Screening Guidelines on Perceptions and Utilization of Low-Dose Computed Tomography. Clin Lung Cancer 2018;19:51-7.

46. Lewis JA, Petty WJ, Tooze JA, et al. Low-dose CT lung cancer screening practices and attitudes among primary care providers at an academic medical center. Cancer Epidemiol Biomarkers Prev 2015;24:664-70.

47. Lewis JA, Chen H, Weaver KE, et al. Low Provider Knowledge Is Associated With Less Evidence-Based Lung Cancer Screening. J Natl Compr Canc Netw 2019;17:339-46.

48. Kanodra NM, Pope C, Halbert CH, et al. Primary care provider and patient perspectives on lung cancer screening: A qualitative study. Ann Am Thorac Soc 2016;13:1977-1982.

49. Hoffman RM, Sussman AL, Getrich CM, et al. Attitudes and Beliefs of Primary Care Providers in New Mexico About Lung Cancer Screening Using Low-Dose Computed Tomography. Prev Chronic Dis 2015;12:E108.

50. Khairy M, Duong DK, Shariff-Marco S, et al. An Analysis of Lung Cancer Screening Beliefs and Practice Patterns for Community Providers Compared to Academic Providers. Cancer Control 2018;25:1073274818806900.

51. Raz DJ, Wu GX, Consunji M, et al. Perceptions and utilization of lung cancer screening among primary care physicians. J Thorac Oncol 2016;11:1856-62.

52. Mukthinuthalapati VVPK, Putta A, Farooq MZ, et al. Knowledge, Attitudes, and Practices Pertaining to Lung Cancer Screening Among Primary Care Physicians in a Public Urban Health Network. Clin Lung Cancer 2020;21:450-4.

53. Leng J, Lei SF, Lei L, et al. Primary Care Providers' Knowledge, Attitudes, Beliefs, and Practice Related to Lung Cancer Screening in Five High-Risk Communities in New York City. J Cancer Educ 2022;37:631-40.

54. Ortmeyer K, Ma GX, Kaiser LR, et al. Effective Educational Approaches to Training Physicians About Lung Cancer Screening. J Cancer Educ 2022;37:52-7.

55. Williams RM, Beck KH, Butler J 3rd, et al. Lung cancer screening decisional needs among African American smokers of lower socioeconomic status. Ethn Health 2022;27:565-83.

56. Crothers K, Kross EK, Reisch LM, et al. Patients' attitudes regarding lung cancer screening and decision aids: A survey and focus group study. Ann Am Thorac Soc 2016;13:1992-2001.

57. Mishra SI, Sussman AL, Murrietta AM, et al. Patient Perspectives on Low-Dose Computed Tomography for Lung Cancer Screening, New Mexico, 2014. Prev Chronic Dis 2016;13:E108.

58. Perez GK, Gareen IF, Sicks JR, et al. Racial Differences in Smoking-related Disease Risk Perceptions Among Adults Completing Lung Cancer Screening: Follow-up Results from the ACRIN/NLST Ancillary Study. J Racial Ethn Health Disparities 2019;6:676-85.

59. Sharma A, Kasza K, Hyland A, et al. Awareness and interest in lung cancer screening among current and former smokers: findings from the ITC United States Survey. Cancer Causes Control 2019;30:733-45.

60. Centers for Medicare and Medicaid Services. Decision Memo for Screening for Lung Cancer with Low Dose Computed Tomography (LDCT) (CAG-00439N). Published 2015. Accessed October 28, 2020. Available online: https://www.cms.gov/medicare-coverage-database/ details/nca-decision-memo.aspx?NCAId=274

61. Volk RJ, Lowenstein LM, Leal VB, et al. Effect of a Patient Decision Aid on Lung Cancer Screening DecisionMaking by Persons Who Smoke: A Randomized Clinical Trial. JAMA Netw open 2020;3:e1920362.

62. Reuland DS, Cubillos L, Brenner AT, et al. A pre-post study testing a lung cancer screening decision aid in primary care. BMC Med Inform Decis Mak 2018;18:5.

63. Goodwin JS, Nishi S, Zhou J, et al. Use of the Shared Decision-Making Visit for Lung Cancer Screening among Medicare Enrollees. JAMA Intern Med 2019;179:716-8.

64. Brenner AT, Malo TL, Margolis M, et al. Evaluating Shared Decision Making for Lung Cancer Screening. JAMA Intern Med 2018;178:1311-6.

65. Rennert L, Zhang L, Lumsden B, et al. Factors influencing lung cancer screening completion following participation in shared decision-making: A retrospective study in a U.S. academic health system. Cancer Treat Res Commun 2020;24:100198.

66. Erkmen CP, Mitchell M, Randhawa S, et al. An Enhanced Shared Decision Making Model to Address Willingness and Ability to Undergo Lung Cancer Screening and FollowUp Treatment in Minority Underserved Populations. J Community Health 2018;43:27-32. 
67. Eberth JM, McDonnell KK, Sercy E, et al. A national survey of primary care physicians: Perceptions and practices of low-dose CT lung cancer screening. Prev Med Rep 2018;11:93-9.

68. Lowenstein M, Vijayaraghavan M, Burke NJ, et al. Realworld lung cancer screening decision-making: Barriers and facilitators. Lung Cancer 2019;133:32-37.

69. Wiener RS, Koppelman E, Bolton R, et al. Patient and Clinician Perspectives on Shared Decision-making in Early Adopting Lung Cancer Screening Programs: a Qualitative Study. J Gen Intern Med 2018;33:1035-42.

70. Zeliadt SB, Hoffman RM, Birkby G, et al. Challenges Implementing Lung Cancer Screening in Federally Qualified Health Centers. Am J Prev Med 2018;54:568-75.

71. Byrne MM, Thurer RJ, Studts JL. Individual decision making about lung cancer screening: A conjoint analysis of perspectives among a high-risk national sample. Cancer Med 2019;8:5779-86.

72. Febbo J, Little B, Fischl-Lanzoni N, et al. Analysis of Outof-Pocket Cost of Lung Cancer Screening for Uninsured

doi: $10.21037 /$ ccts-20-173

Cite this article as: Toubat $\mathrm{O}$, David EA. A narrative review of lung cancer screening in underserved populations. Curr Chall Thorac Surg 2023;5:6.
Patients Among ACR-Accredited Imaging Centers. J Am Coll Radiol 2020;17:1108-15.

73. McKee BJ, McKee AB, Flacke S, et al. Initial experience with a free, high-volume, low-dose ct lung cancer screening program. J Am Coll Radiol 2013;10:586-92.

74. Simmerman EL, Thomson NB, Dillard TA, et al. Free Lung Cancer Screening Trends Toward a Twofold Increase in Lung Cancer Prevalence in the Underserved Southeastern United States. South Med J 2017;110:188-94.

75. Chung JM, Simmerman EL, Sadek RF, et al. Financial Analysis of Free Lung Cancer Screening Program Shows Profitability Using Broader NCCN Guidelines. Ann Thorac Surg 2019;107:885-90.

76. Raghavan D, Wheeler M, Doege D, et al. Initial Results from Mobile Low-Dose Computerized Tomographic Lung Cancer Screening Unit: Improved Outcomes for Underserved Populations. Oncologist 2020;25:e777-81.

77. Headrick JR Jr, Morin O, Miller AD, et al. Mobile Lung Screening: Should We All Get on the Bus?. Ann Thorac Surg 2020;110:1147-52. 